\title{
黄河口潮间带沉积物细菌群落结构特征
}

\author{
尹 霞 ${ }^{1,2,3}$, 李思琦 ${ }^{2,3,4}$, 尚天微 ${ }^{2,5}$, 江雪艳 ${ }^{2,5}$, 甄 毓 $1,2,3, *$ \\ 1 中国海洋大学环境科学与工程学院,青岛 266100 \\ 2 青岛海洋科学与技术国家实验室海洋生态与环境科学功能实验室,青岛 266237 \\ 3 海洋环境与生态教育部重点实验室, 青岛 266100 \\ 4 中国海洋大学海洋生命学院,青岛 266003 \\ 5 中国海洋大学化学化工学院,青岛 266100
}

\begin{abstract}
摘要: 选取黄河口潮间带有植被覆盖和无植被覆盖两个区域采集柱状沉积物, 利用实时菼光定量 PCR 技术和高通量测序技术 分析有无植被覆盖沉积物中的细菌群落特征和功能差异, 探究影响潮间带细菌群落结构的主要环境因子。结果显示, 细菌丰度 在有植被区域大于无植被区域。沉积物中细菌群落丰富度和多样性在有植被区域随深度的增加而增加, 而在无植被区域其最 高值出现在沉积物中层 $(14-16 \mathrm{~cm})$ 。两个区域在门分类水平上以变形菌 (Proteobacteria)、绿弯菌 (Chloroflexi)、放线菌 (Actinobacteria) 和酸杆菌 (Acidobacteria) 为主; 属分类水平上的优势类群为芽狍杆菌 (Bacillus) 、苍白杆菌 (Ochrobactrum)、拟无 枝菌酸菌(Amycolatopsis) 和鞘脂单胞菌(Sphingomonas) 等。相关性分析发现盐度和亚硝酸盐浓度对细菌群落多样性和丰富度 影响显著。功能预测分析表明,有植被区域沉积物细菌在氨基酸代谢、膜运输和碳水化合物代谢方面功能活跃,而无植被区域 细菌则在核酸复制和修复、能量代谢过程方面更为活跃。
\end{abstract}

关键词:黄河口;潮间带; 细菌; 群落结构

\section{Characteristics of bacterial community structure in intertidal sediments of the Yellow River estuary}

\author{
YIN Xia ${ }^{1,2,3}$, LI Siqi ${ }^{2,3,4}$, SHANG Tianwei ${ }^{2,5}$, JIANG Xueyan ${ }^{2,5}$, ZHEN Yu ${ }^{1,2,3, *}$ \\ 1 College of Environmental Science and Engineering, Ocean University of China, Qingdao 266100, China \\ 2 Laboratory for Marine Ecology and Environmental Science, Qingdao National Laboratory for Marine Science and Technology, Qingdao 266237, China \\ 3 Key Laboratory of Marine Environment and Ecology, Ministry of Education, Qingdao 266100, China \\ 4 College of Marine Life Science, Ocean University of China, Qingdao 266003, China \\ 5 College of Chemistry and Chemical Engineering, Ocean University of China, Qingdao 266100, China
}

\begin{abstract}
In this study, the sediment cores were collected from two areas with or without vegetation covering in the intertidal zone of the Yellow River estuary, in which the characteristics and functional differences of bacterial community were analyzed based on real-time fluorescent quantitative PCR and high-throughput sequencing. The mainly environmental influencing factors were also explored. Results showed that the bacterial abundance from the vegetation area was higher than that from the vegetation-free area. The richness and diversity of bacterial community increased with the depth in the vegetation area, while they were the highest in the sample of middle layer $(14-16 \mathrm{~cm})$ in the vegetation-free area. The shared dominant phyla in both areas were Proteobacteria, Chloroflexi, Actinobacteria and Acidobacteria. The dominant

基金项目: 国家自然科学基金项目 (41876077) ; 青岛海洋科学与技术试点国家实验室海洋生态与环境科学功能实验室青年人才培育项目 ( LMEES-YTSP-2018-02-06) ; 中央高校基本科研业务项目 (201962003)

收稿日期: 2020-08-02; 网络出版日期:2021-07-05

* 通讯作者 Corresponding author.E-mail: zhenyu@ ouc.edu.cn
\end{abstract}


genera were Bacillus, Ochrobactrum, Amycolatopsis, Sphingomonas and so on. The results of correlation analysis showed that salinity and nitrite concentration were the main influencing factors of the richness and diversity of bacterial community. The functional prediction analysis showed that the processes of bacterial membrane transport, amino acid metabolism and carbohydrate metabolism in the vegetation area were more active, while the processes of bacterial DNA replication, repairing and energy metabolism in the vegetation-free area were more active.

Key Words: Yellow River estuary; intertidal zone; bacteria; community structure

黄河口潮间带位于渤海湾南岸和莱州湾西岸, 属盐碱湿地 ${ }^{[1]}$ 。黄河口潮间带湿地是我国暖温带保存最 完整、最年轻、发展速度最快的湿地。该区域蕴藏着丰富的石油和生物资源, 尤其有一些濒危鸟类在此栖息， 维持该生态系统的稳定对保护自然资源和生物多样性具有重要意义。

微生物是潮间带湿地生态系统的重要组成部分。与其它生物相比,微生物具有体积小、种类多、分布广、 繁殖快、代谢能力强和易变异等特点, 能及时反映出所处环境的变化 ${ }^{[2]}$ 。对于微生物而言, 潮间带不是一个 良好的生存环境。潮间带微生物必须应对高温、紫外线辐射、不规律的干旱与淹没等重重考验, 以及由于争夺 养分和空间而产生的激烈的生物相互作用 ${ }^{[3]}$ 。这些环境因子的限制可能有利于某些具有特殊生理和代谢功 能微生物的生存和发展。研究环境微生物结构和功能, 有助于发现和利用新的重要的微生物资源, 对探究微 生物群落和生境的关系,指导微生物群落功能的定向调控具有重要意义。

有研究指出湿地植被组成及土壤性质是影响湿地土壤微生物群落组成和功能活性的重要因素 ${ }^{[4]}$ 。植被 是潮间带生态系统初级生产力的重要来源, 在维持该生态系统相关功能中发挥关键作用 ${ }^{[5]}$ 。植物光合作用 近 30\%的产物可以通过植物根系释放到土壤中被微生物利用 ${ }^{[6]}$, 而微生物也可以通过自身代谢活动将土壤 中有机物降解为无机物供植物吸收利用, 促进植物生长。由此可见, 潮间带植物与土壤微生物具有密切联系。 对黄河口潮间带沉积物中微生物的研究已有一些报道 ${ }^{[7-9]}$ 。已有的研究主要分析了黄河口潮间带沉积物中 微生物的群落结构, 却没有对有植被与无植被沉积物中细菌群落结构及其潜在功能进行比较分析。本研究选 取黄河口潮间带表面覆盖有植被和表面无植被的两个区域, 对比了解两个区域沉积物中细菌群落结构和功 能, 为黄河口潮间带生态系统的保护以及充分利用潮间带微生物资源提供依据, 对研究潮间带生态系统的运 行机制、功能,表征潮间带环境变化, 维持其平稳运作具有指导作用 ${ }^{[10]}$ 。

\section{1 材料和方法}

\section{1 样品的采集与保存}

2019 年 3 月 20 日- 21 日于黄河口潮间带分别选择表面无植被( UT) 的光滩区域和表面长有芦苇植被 (VT) 区域设置采样站位(图 1)。将直径为 $11 \mathrm{~cm}$ 、长为 $30 \mathrm{~cm}$ 的 PVC 管打入潮间带沉积物中采集柱状样品, 以每 $2 \mathrm{~cm}$ 的间隔进行切割, 分装于无菌的聚氯乙烯塑料封口袋, 储存于 $-20{ }^{\circ} \mathrm{C}$ 冰箱, 运送至实验室后于 -80 ${ }^{\circ} \mathrm{C}$ 保存, 用于 DNA 的提取。每个采样点分别挖一个深度约为 $40 \mathrm{~cm}$ 的坑,在纵切面上利用 Rhizon 土壤溶液采 样器 (荷兰) 以每 $2 \mathrm{~cm}$ 的间隔采集间隙水样品, 经 $0.45 \mu \mathrm{m}$ 滤膜过滤后, 将水样分为两份, 一份在现场测定盐 度、 $\mathrm{pH}$, 另一份保存在 $-20^{\circ} \mathrm{C}$ 冰箱, 带回实验室后测定硫酸盐、铵盐、硝酸盐、亚硝酸盐和磷酸盐含量等参数。

\section{2 理化参数的测定}

利用 Multi 3620 IDS 多参水质检测仪 (德国) 对不同深度采集的间隙水样的 $\mathrm{pH}$ 、盐度进行现场测定; 利用 营养盐自动分析仪 (Quaatro Bran-Lubbe Ltd.) 对间隙水中硝酸盐、亚硝酸盐、铵盐和磷酸盐四种营养盐含量进 行测定;间隙水中硫酸根离子的浓度利用 ICS-3000 离子色谱仪( DIONEX，USA) 进行测定。

\subsection{DNA 提取}

利用 Power Soil ${ }^{\circledR}$ Isolation Kit(MO Bio Laboratories, USA) DNA 提取试剂盒分别对不同深度沉积物样品 


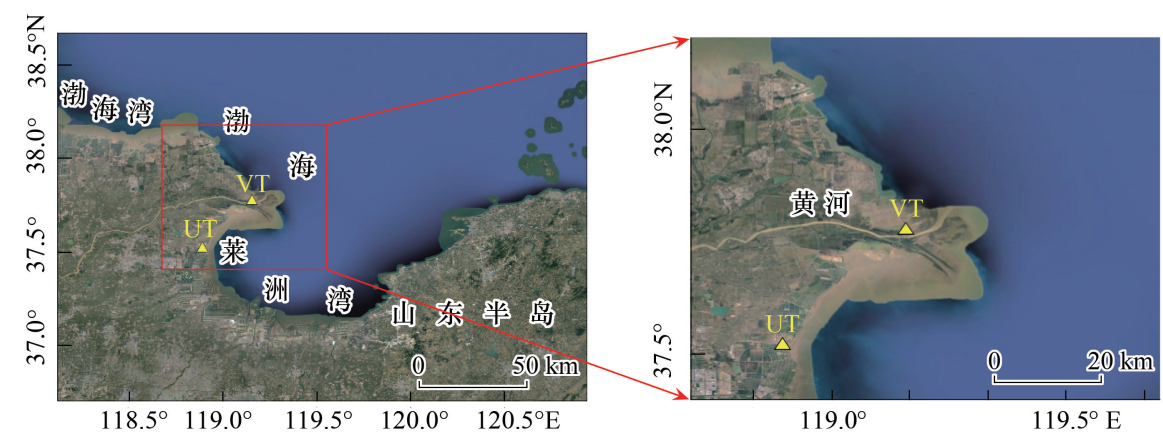

图 1 黄河口潮间带柱状沉积物采样点

Fig.1 Location of sampling site in the intertidal mudflat of the Yellow River estuary

VT: 有植被 Vegetation; UT: 无植被 Vegetation-free

的总基因组 DNA 进行提取, 参照试剂盒的说明书进行操作。利用超微量分光光度计 (Thermo Scientific, USA) 对提取的 DNA 样液进行质量和浓度检测, 检测合格后, 挑选柱状样的表层 $(0-2 \mathrm{~cm})$ 、次表层 $(2-4$ $\mathrm{cm})$ 、中层 $(14-16 \mathrm{~cm})$ 和底层 $(28-30 \mathrm{~cm})$ 的 DNA 样品送于测序公司进行高通量测序。

1.4 Illumina 高通量测序

以提取的 DNA 为 PCR 模板, 用带有测序标签 barcode 的引物 338F (ACTCCTACGGGAGGCAGCAG)/ 806R (GGACTACNSGGGTWTCTAAT) ${ }^{[11]}$ 对样品基因目标片段进行扩增, 扩增条件为: $94{ }^{\circ} \mathrm{C}, 10 \mathrm{~min}$; $94{ }^{\circ} \mathrm{C}$,

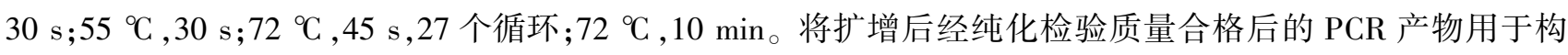
建测序文库,使用 Illumina Sequencer MiSeq 测序仪进行 $2 \times 300$ bp 的双端测序。利用 QIIME 软件对高通量测 序下机的原始数据进行识别, 剔除长度小于 $160 \mathrm{bp}$ 及存在模糊碱基的问题序列, 再调用 USEARCH 对嵌合体 序列进行检查并剔除, 评估得到的有效序列的质量, 从而获得可用于后续分析的优质序列。使用 USEARCH 软件对上述过程得到的序列以 $97 \%$ 的序列相似度进行归并和可操作分类单元 (operational taxonomic units, OTU) 划分, 挑选出每个 OTU 中丰度最高的序列作为该 OTU 的代表序列, 用 RDF classifier 将其与 Silva 数据库 比对进行注释, 以供后续分析。

\section{5 实时苂光定量 PCR 检测}

利用 $\mathrm{qPCR}$ 对有植被和无植被两个研究区域 $0-30 \mathrm{~cm}$ 的每隔 $2 \mathrm{~cm}$ 的土壤样品细菌丰度进行了测定。 配制 $20 \mu \mathrm{L}$ 的 qPCR 反应体系: $10 \mu \mathrm{L}$ ROX (FastStart Universal SYBR Green Master, Roche, 瑞士), 正反向引物 (338F/806R) 各 $0.6 \mu \mathrm{L}, 0.2 \mu \mathrm{L}$ 牛血清蛋白, $6.6 \mu \mathrm{L}$ 超纯水和 $2 \mu \mathrm{L} \mathrm{DNA}$ 模板。每个样品设置 3 个平行实验, 每组反应添加阴性对照。反应在 ABI7500 苂光定量 PCR 仪上进行, 反应条件设置为: $94{ }^{\circ} \mathrm{C}, 10 \mathrm{~min} ; 94{ }^{\circ} \mathrm{C}$, $30 \mathrm{~s} ; 58{ }^{\circ} \mathrm{C}, 45 \mathrm{~s} ; 72{ }^{\circ} \mathrm{C}, 1 \mathrm{~min}, 35$ 个循环; $72{ }^{\circ} \mathrm{C}, 10 \mathrm{~min}_{\text {。 }}$ 反应结束后通过熔融曲线判断扩增的特异性, 并用 $2 \%$ 琼脂糖凝胶电泳分析扩增效果。

\subsection{PICRUSt 功能预测}

PICRUSt 方法是基于已测细菌基因组的 $16 \mathrm{~S}$ rRNA 全长序列, 推断它们共同祖先的基因功能谱, 对 Greengenes 数据库中其它未测物种的基因功能谱进行推断, 构建古菌和细菌域全谱系的基因功能预测谱, 最 后将测序得到的菌群组成“映射”到数据库中,完成对菌群代谢功能的预测。

\section{7 数据分析与处理}

利用 EXCEL 2010 和 Origin 2018 对实验数据(细菌丰度、群落结构) 进行初步处理与制图。通过 SPSS Statistics 25 软件对数据进行单因素方差分析。应用 R 3.6.1 软件的“pheatmap” 和“vegan”程序包,对细菌属进 行聚类分析并绘制热图 ${ }^{[12]}$ 。使用 CANOCO 4.5 软件对环境因子与群落结构进行典范对应分析 (Canonical correspondence analysis, CCA)。 


\section{2 结果与分析}

\section{1 环境因子特征}

对黄河口潮间带间隙水中环境因子的测定结果见表 1 。两个研究区域的盐度均随沉积物深度的增加而 降低,有植被区域盐度梯度变化尤其显著, 由表层的 35 降低到底层为 $4.17 。 \mathrm{pH}$ 值随沉积物深度的变化较小, 有植被区域 $\mathrm{pH}$ 值为 7.73-7.88, 无植被区域为 7.18-7.44。硫酸盐浓度在两个站位的差异性显著 $(P<0.05)$, 在无植被区域浓度介于 $17.40-28.79 \mathrm{mmol} / \mathrm{L}$ 之间,而在有植被区域,表层浓度高达 $69.89 \mathrm{mmol} / \mathrm{L}$, 约为该区 域最低浓度的 100 倍。铵盐、亚硝酸盐和磷酸盐含量整体表现为有植被区域高于无植被区域。

表 1 黄河口潮间带间隙水理化参数

Table 1 Physical and chemical parameters of columnar sediment in the intertidal mudflat of Yellow River estuary

\begin{tabular}{|c|c|c|c|c|c|c|c|c|c|}
\hline $\begin{array}{l}\text { 地表特征 } \\
\text { Surface feature }\end{array}$ & $\begin{array}{c}\text { 深度 } \\
\text { Depth/cm }\end{array}$ & $\begin{array}{l}\text { 样品 } \\
\text { Sample }\end{array}$ & $\begin{array}{c}\text { 盐度 } \\
\text { Salinity }\end{array}$ & $\mathrm{pH}$ & $\begin{array}{c}\text { 硫酸盐 } \\
\text { Sulfate/ } \\
(\mathrm{mmol} / \mathrm{L})\end{array}$ & $\begin{array}{c}\text { 铵盐 } \\
\text { Ammonium salt/ } \\
(\mu \mathrm{mol} / \mathrm{L})\end{array}$ & $\begin{array}{c}\text { 亚硝酸盐 } \\
\text { Nitrite/ } \\
(\mu \mathrm{mol} / \mathrm{L})\end{array}$ & $\begin{array}{c}\text { 硝酸盐 } \\
\text { Nitrate/ } \\
(\mu \mathrm{mol} / \mathrm{L})\end{array}$ & $\begin{array}{c}\text { 磷酸盐 } \\
\text { Phosphate/ } \\
(\mu \mathrm{mol} / \mathrm{L})\end{array}$ \\
\hline 有植被 & $0-2$ & VT1 & 35.00 & 7.80 & 69.89 & 231.57 & 0.37 & 0.32 & 1.57 \\
\hline \multirow[t]{3}{*}{ Vegetation } & $2-4$ & VT2 & 30.00 & 7.73 & 2.29 & 339.92 & 0.11 & 0.25 & 0.21 \\
\hline & $14-16$ & VT3 & 6.51 & 7.78 & 0.69 & 177.53 & 0.04 & 0.38 & 0.20 \\
\hline & $28-30$ & VT4 & 4.17 & 7.88 & 1.54 & 80.42 & 0.04 & 0.21 & 0.27 \\
\hline 无植被 & $0-2$ & UT1 & 22.70 & 7.18 & 28.79 & 130.75 & 0.07 & 0.72 & 0.02 \\
\hline \multirow[t]{3}{*}{ Vegetation-free } & $2-4$ & UT2 & 21.71 & 7.22 & 22.27 & 113.19 & 0.17 & 0.78 & 0.01 \\
\hline & $14-16$ & UT3 & 14.84 & 7.44 & 17.40 & 4.82 & 0.07 & 5.10 & 0.13 \\
\hline & $28-30$ & UT4 & 14.14 & 7.27 & 24.17 & 38.94 & 0.03 & 0.62 & 0.01 \\
\hline
\end{tabular}

\section{2 细菌 $16 \mathrm{~S}$ rRNA 基因丰度}

从表层有植被和表层无植被区域的细菌丰度垂直分布图 (图 2) 可以看出,细菌丰度在不同区域、不同深 度有明显变化。在两个区域, 细菌丰度峰值均出现在中层, 表层和底层丰度相对较低。在相同深度的沉积物 样品中细菌丰度在有植被区域比无植被区域高, 有植被区域细菌丰度为 $3.55 \times 10^{5}-1.29 \times 10^{7}$ 拷贝数 $/ \mathrm{g}$, 无植 被区域细菌丰度为 $5.76 \times 10^{2}-4.23 \times 10^{6}$ 拷贝数 $/ \mathrm{g}$, 说明有植被环境可以为细菌提供更适宜的生存和发展环 境。对荧光定量 PCR 产物进行的凝胶电泳结果显示均为明亮的单条带, 说明扩增的特异性 (图 3)。

2.3 细菌群落多样性

所有样品中细菌测序覆盖度均高于 $96.14 \%$,说明测序深度覆盖了大多数细菌物种,基本能够反映样品中 细菌的群落信息。经质控后, 8 个样品共获得 126647 条有效序列, 97\% 的相似性聚类得到 12070 个 OTUs (表 2)。在有植被区域沉积物中,丰富度指数 Chao 1 由表层到底层逐渐增加,多样性指数 Shannon 在底层样 品中最高。无植被区域沉积物中细菌群落的丰富度和多样性在中层样品表现为最高。

表 2 黄河口潮间带柱状沉积物细菌的 $\alpha$-多样性指数

Table $2 \alpha$-diversity indices of bacterial communities of columnar sediment in the intertidal mudflat of Yellow River estuary

\begin{tabular}{lccccccc}
\hline $\begin{array}{l}\text { 地表特征 } \\
\text { Surface feature }\end{array}$ & $\begin{array}{c}\text { 深度 } \\
\text { Depth/cm }\end{array}$ & $\begin{array}{c}\text { 样品 } \\
\text { Sample }\end{array}$ & $\begin{array}{c}\text { 序列条数 } \\
\text { Sequence } \\
\text { number }\end{array}$ & $\begin{array}{c}\text { OTU 个数 } \\
\text { OTU number }\end{array}$ & $\begin{array}{c}\text { 丰富度指数 } \\
\text { Chao 1 }\end{array}$ & $\begin{array}{c}\text { 多样性指数 } \\
\text { Shannon }\end{array}$ & $\begin{array}{c}\text { 覆盖度 } \\
\text { Coverage/\% }\end{array}$ \\
\hline 有植被 & $0-2$ & VT1 & 15931 & 1000 & 1000 & 6.34 & 97.38 \\
Vegetation & $2-4$ & VT2 & 16094 & 1556 & 1556 & 9.12 & 97.33 \\
& $14-16$ & VT3 & 15749 & 1874 & 1879 & 8.99 & 96.14 \\
& $28-30$ & VT4 & 15685 & 2735 & 2917 & 10.38 & 96.37 \\
无植被 & $0-2$ & UT1 & 15852 & 2011 & 2215 & 8.75 & 97.42 \\
Vegetation-free & $2-4$ & UT2 & 15883 & 1888 & 2000 & 9.00 & 98.77 \\
& $14-16$ & UT3 & 15836 & 2514 & 2690 & 9.92 & 96.96 \\
& $28-30$ & UT4 & 15617 & 2214 & 2416 & 9.77 & 98.34 \\
\hline
\end{tabular}




\section{4 细菌群落结构}

对有植被和无植被两个生境不同深度沉积物样品 的细菌群落在门分类水平上进行了分析,有植被区域共 检测到 50 个细菌门,无植被共 56 个细菌门。选取其中 相对丰度 $>1.0 \%$ 的细菌进行作图。从图 4 可以看出黄 河口潮间带沉积物两个研究区域的细菌群落主要优势 细菌为变形菌 (Proteobacteria)、绿弯菌 (Chloroflexi) 和 放线菌 (Actinobacteria), 相对丰度和为 $59.0 \%-80.0 \%$ 。 无植被表层样品 (UT2) 的最优势菌是绿弯菌 (28.1\%)， 除此之外, 其它样品中相对丰度最高的均为变形菌, 为 $28.4 \%-49.6 \%$ 。两个研究区域沉积物中酸杆菌 (Acidobacteria) 的相对丰度都是随着深度的增加而增 加。不同细菌门在各个样品中的相对丰度表现出差异, 其中有植被区域表层样品 (VT1) 与其它样品差异尤为 显著。如绿弯菌在其它样品中相对丰度较高, 占 $14.8 \%-28.1 \%$, 在 VT1 中相对丰度仅为 $1.3 \%$, 而放线 菌丰度高达 $29.0 \%$, 蓝细菌丰度为 $3.8 \%$, 酸杆菌丰度与 其它样品相比较低,仅为 $0.4 \%$ 。

根据属分类水平上细菌的注释信息,选择所有样品 中相对丰度排在前 20 的属, 对物种和样品进行聚类,绘 制聚类热图(图 5)。不同颜色代表不同丰度,颜色越红 代表该属在对应样品中丰度越高,蓝色越深则表示该属 的丰度越低。结果显示,各样品的优势菌属表现出较大
$16 \mathrm{~S}$ rRNA基因搭贝数 $16 \mathrm{~S}$ rRNA gene copy numbers/(拷贝数 $/ \mathrm{g}$ ) $1.0 \times 10^{3} \quad 1.0 \times 10^{4} \quad 1.0 \times 10^{5} \quad 1.0 \times 10^{6} \quad 1.0 \times 10^{7}$

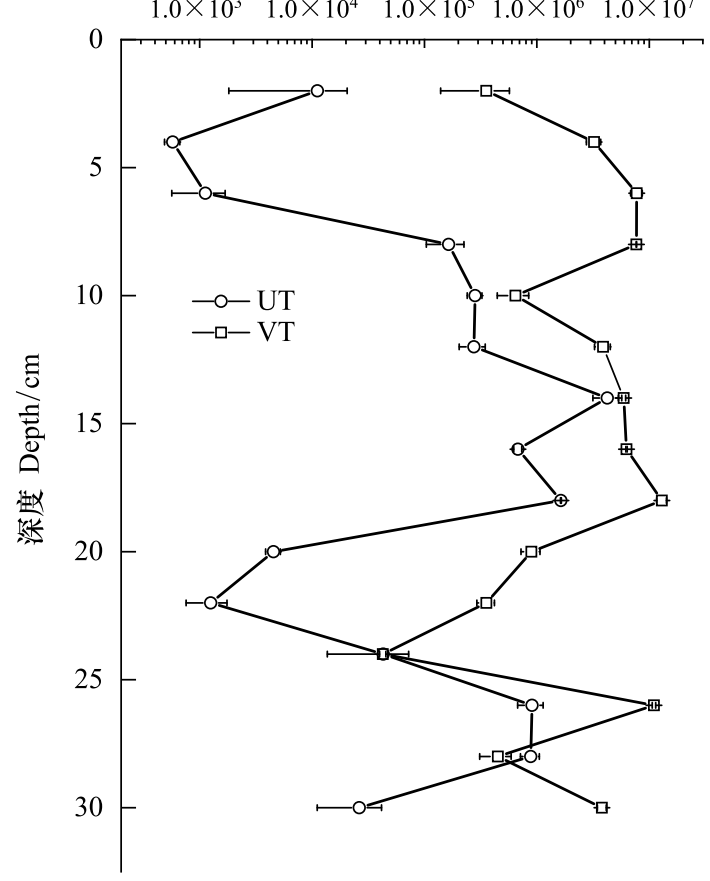

图 2 黄河口潮间带不同深度沉积物中细菌 16S rRNA 基因丰度 Fig.2 The bacterial 16S rRNA gene abundances of columnar sediment in the intertidal mudflat of Yellow River estuary

$\mathrm{VT}$ : 有植被 Vegetation; UT: 无植被 Vegetation-free

的差异, UT1、UT2、VT1、VT3 聚为一组, UT3、UT4、VT2、VT4 聚为一组, 表明两个区域优势菌属组成差异不明

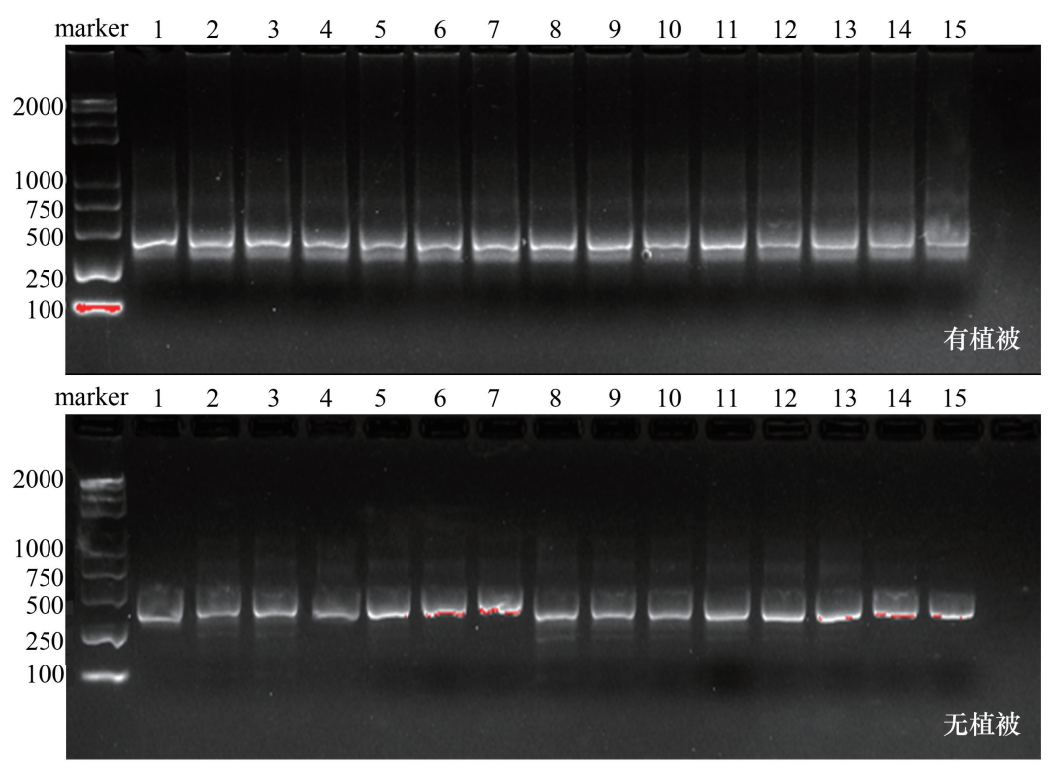

图 3 荧光定量 PCR 产物凝胶电泳图

Fig.3 Gel electrophoresis image of realtime fluorescent quantitative PCR products 


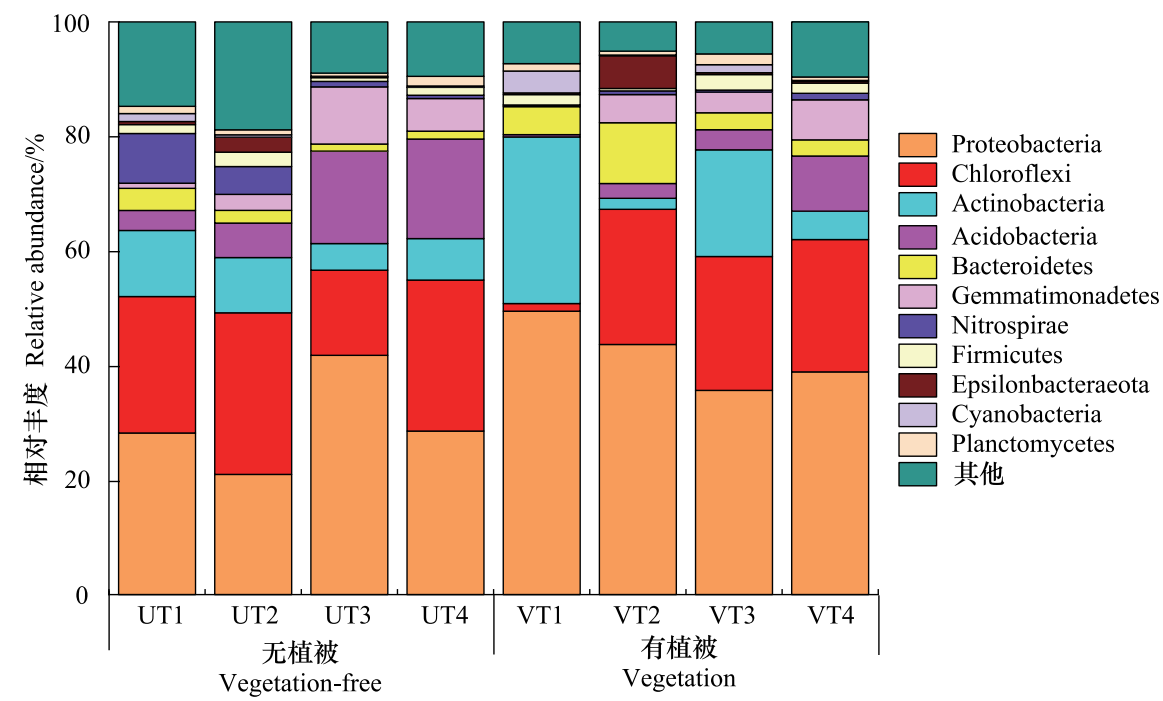

图 4 门分类水平上细菌的组成及丰度分布

Fig.4 The composition and abundance distribution of bacterial communities at phylum level

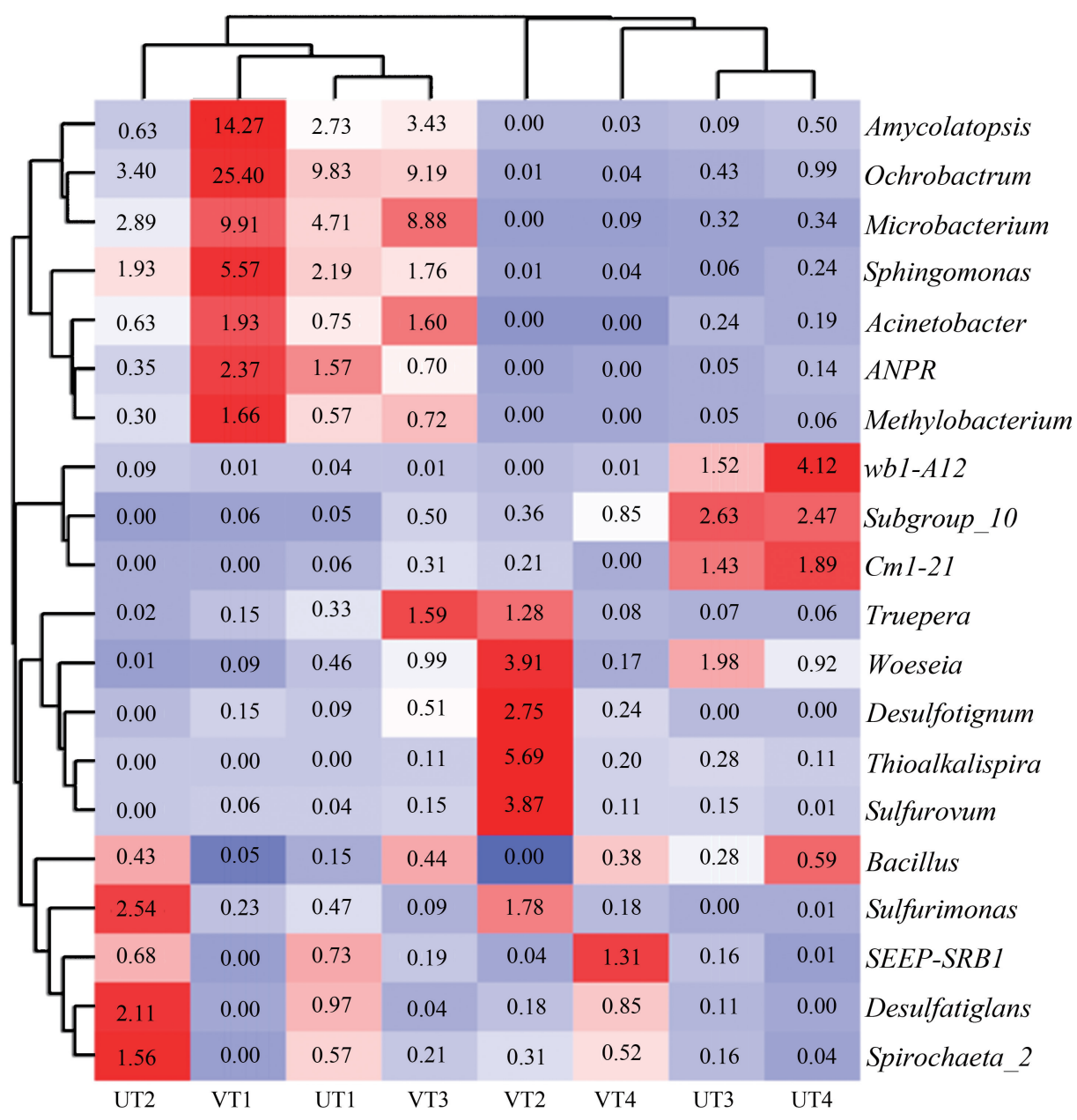

图 5 黄河口潮间带沉积物中细菌属分类水平丰度热图

Fig.5 Genus abundance heatmap of bacterial community in the intertidal zone of Yellow River estuary 
显。其中苍白杆菌 (Ochrobactrum) 在多个样品中为最优势菌属, 尤其在有植被表层样品中相对丰度达 $25.4 \%$, 在无植被表层样品中占 $9.8 \%$ 。芽孢杆菌 (Bacillus) 、拟无枝菌酸菌 (Amycolatopsis) 和鞘脂单胞菌 (Sphingomonas) 等菌属分别在不同样品中丰度显著。

\section{5 细菌群落结构与环境因子的相关分析}

典范对应分析 (CCA) 结果显示 (图 6),第一和第二 排序轴共解释了样本与环境因子间 $41.5 \%$ 的累计变量。 表 3 显示与第一排序轴相关性较高的环境因子有铵盐 $(0.7462)$ 和硝酸盐 $(-0.5396)$, 与第二排序轴相关性较 高的环境因子是亚硝酸盐 $(-0.4518)$ 和硫酸盐 $(-0.5189)$ 。

利用 SPSS 软件分别对环境因子与多样性和丰富 度 (表 4)、环境因子与优势菌门(表 5) 进行了相关性分 析。其中 Chao 1 指数和 Shannon 指数均与盐度呈显著 负相关 $(P<0.05)$; Shannon 指数与亚硝酸盐和磷酸盐呈 极显著负相关 $(P<0.01)$ 。说明盐度、亚硝酸盐和磷酸 盐是影响黄河口潮间带沉积物中细菌群落丰富度和多 样性的重要因素。优势菌门与环境因子的相关分析结 果显示, 变形菌 (Proteobacteria) 的含量与 $\mathrm{pH}$ 呈显著正 相关 $(P<0.05)$; 绿弯菌 (Chloroflexi) 与硫酸盐、亚硝酸 盐和磷酸盐均呈显著负相关 $(P<0.05)$, 而蓝细菌 (Cyanobacteria) 与之相反, 呈显著正相关 $(P<0.05)$; 放 线菌 (Actinobacteria) 与硫酸盐和磷酸盐呈显著正相关

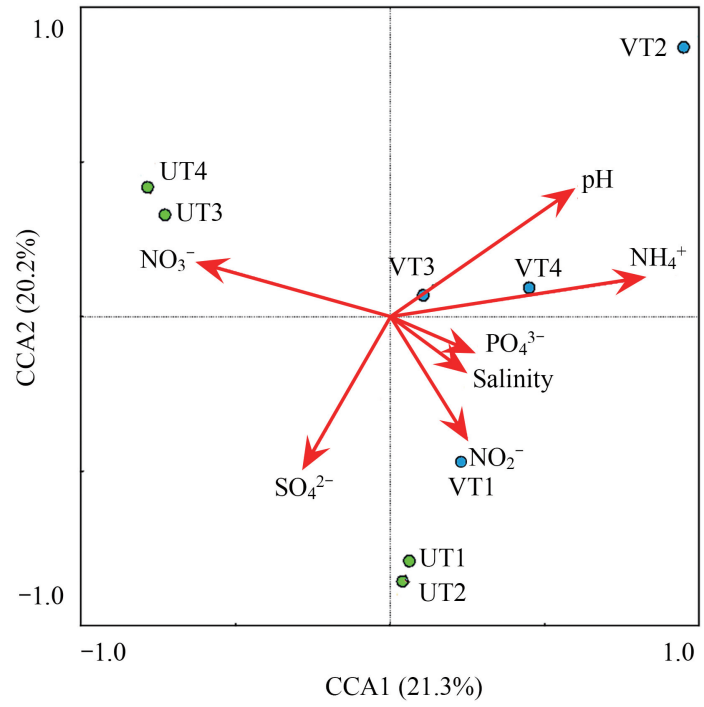

图 6 细菌群落与环境因子典范对应分析

Fig.6 Canonical correlation analysis between bacterial community and environmental factors

$\mathrm{NH}_{4}^{+}$: 铵盐 Ammonium salt; $\mathrm{NO}_{3}^{-}$: 硝酸盐 Nitrate; $\mathrm{NO}_{2}^{-}$: 亚硝酸盐 Nitrite; $\mathrm{SO}_{4}^{2-}$ : 硫酸盐 Sulfate; $\mathrm{PO}_{4}^{3-}$ : 磷酸盐 Phosphate $(P<0.05)$; 酸杆菌 (Acidobacteria) 与铵盐浓度呈显著负相关 $(P<0.05)$; 拟杆菌 (Bacteroidetes) 与铵盐呈极显著 正相关 $(P<0.01)$ 。盐度、硝酸盐浓度与优势菌门相关性不显著 $(P>0.05)$ 。说明沉积物的理化性质对微生物 群落结构具有重要影响。

表 3 环境因子与细菌群落分析中前两个排序轴间的相关系数

Table 3 Correlation coefficients of environmental factors with the first two axes of CCA of bacterial community

\begin{tabular}{lcccccrr}
\hline $\begin{array}{l}\text { 排序轴 } \\
\text { Sorting axis }\end{array}$ & $\begin{array}{c}\text { 盐度 } \\
\text { Salinity }\end{array}$ & $\mathrm{pH}$ & $\begin{array}{l}\text { 硫酸盐 } \\
\text { Sulfate }\end{array}$ & $\begin{array}{c}\text { 铵盐 } \\
\text { Ammonium salt }\end{array}$ & $\begin{array}{r}\text { 硝酸盐 } \\
\text { Nitrate }\end{array}$ & $\begin{array}{c}\text { 亚硝酸盐 } \\
\text { Nitrite }\end{array}$ & $\begin{array}{r}\text { 磷酸盐 } \\
\text { Phosphate }\end{array}$ \\
\hline 排序轴 1 Axis 1 & 0.3315 & 0.5236 & -0.3731 & 0.7462 & -0.5396 & 0.0632 & 0.3596 \\
排序轴 2 Axis 2 & -0.1860 & 0.4696 & -0.5189 & -0.3778 & 0.3977 & -0.4518 & -0.0223 \\
\hline
\end{tabular}

表 4 多样性和丰富度与环境因子的相关系数矩阵

Table 4 Correlation coefficient matrix of Chao 1, Shannon and environmental factors

\begin{tabular}{|c|c|c|c|c|c|c|c|}
\hline $\begin{array}{l}\alpha \text { 多样性指数 } \\
\text { Alpha diversity index }\end{array}$ & $\begin{array}{c}\text { 盐度 } \\
\text { Salinity }\end{array}$ & $\mathrm{pH}$ & $\begin{array}{l}\text { 硫酸盐 } \\
\text { Sulfate }\end{array}$ & $\begin{array}{c}\text { 铵盐 } \\
\text { Ammonium salt }\end{array}$ & $\begin{array}{l}\text { 硝酸盐 } \\
\text { Nitrate }\end{array}$ & $\begin{array}{l}\text { 亚硝酸盐 } \\
\text { Nitrite }\end{array}$ & $\begin{array}{c}\text { 磷酸盐 } \\
\text { Phosphate }\end{array}$ \\
\hline Chao 1 & $-0.787^{*}$ & -0.253 & -0.561 & $-0.799^{*}$ & 0.411 & $-0.797^{*}$ & -0.685 \\
\hline Shannon & $-0.757^{*}$ & -0.165 & $-0.830^{*}$ & -0.539 & 0.294 & $-0.900 * *$ & $-0.839^{* *}$ \\
\hline
\end{tabular}

$*$ : 在 0.05 级别 (双尾), 相关性显著; **: 在 0.01 级别 (双尾), 相关性显著

2.6 PICRUSt 功能预测分析

为了解表层有植被和表层无植被沉积物中细菌群落功能的不同以及其在垂直方向上的变化,使用 PICRUSt 对两个区域不同深度沉积物样品的细菌群落进行功能预测 (图 7)。结果共注释到 6 条 KEGG一级 通路,其中相对丰度大于 $1.0 \%$ 的功能基因有环境信息处理 (Environmental Information Processing)、代谢 
(Metabolism)、遗传信息处理( Genetic Information Processing) 和细胞转化( Cellular Processes) 4 种。注释到 41 条 KEGG 二级代谢通路, 其中在所有样品中相对丰度在 $1.0 \%$ 以上的通路有 19 个, 如膜运输 (Membrane Transport)、氨基酸代谢(Amino Acid Metabolism) 和碳水化合物代谢(Carbohydrate Metabolism)在两个区域的 相对丰度均较高, 超过 10\%; 复制和修复 (Replication and Repair) 与能量代谢 (Energy Metabolism) 两种通路的 相对丰度也高于 $5 \%$ 。相比较而言,膜转运过程、氨基酸和碳水化合物代谢过程在有植被区域更为活跃,而核 酸复制和修复、能量代谢过程则在无植被区域更加活跃。

表 5 细菌与环境因子的相关系数矩阵

Table 5 Correlation coefficient matrix of bacteria and environmental factors

\begin{tabular}{|c|c|c|c|c|c|c|c|}
\hline $\begin{array}{l}\text { 细菌 } \\
\text { Bacteria }\end{array}$ & $\begin{array}{c}\text { 盐度 } \\
\text { Salinity }\end{array}$ & $\mathrm{pH}$ & $\begin{array}{l}\text { 硫酸盐 } \\
\text { Sulfate }\end{array}$ & $\begin{array}{c}\text { 铵盐 } \\
\text { Ammonium salt }\end{array}$ & $\begin{array}{l}\text { 硝酸盐 } \\
\text { Nitrate }\end{array}$ & $\begin{array}{c}\text { 亚硝酸盐 } \\
\text { Nitrite }\end{array}$ & $\begin{array}{c}\text { 磷酸盐 } \\
\text { Phosphate }\end{array}$ \\
\hline 变形菌 Proteobacteria & 0.287 & $0.775^{*}$ & 0.228 & 0.422 & 0.139 & 0.401 & 0.696 \\
\hline 绿弯菌 Chloroflexi & -0.486 & -0.424 & $-0.745^{*}$ & -0.189 & -0.211 & $-0.747^{*}$ & $-0.909^{* *}$ \\
\hline 放线菌 Actinobacteria & 0.335 & 0.255 & $0.723^{*}$ & 0.258 & -0.288 & 0.706 & $0.786^{*}$ \\
\hline 酸杆菌 Acidobacteria & -0.523 & -0.357 & -0.244 & $-0.823^{*}$ & 0.575 & -0.552 & -0.475 \\
\hline 拟杆菌 Bacteroidetes & 0.592 & 0.396 & -0.081 & $0.922^{* *}$ & -0.396 & 0.262 & 0.222 \\
\hline 硝化螺旋菌 Nitrospirae & 0.134 & -0.692 & 0.069 & -0.137 & -0.065 & -0.126 & -0.387 \\
\hline 蓝细菌 Cyanobacteria & 0.521 & 0.28 & $0.810^{*}$ & 0.375 & -0.287 & $0.792 *$ & $0.875^{* *}$ \\
\hline
\end{tabular}

$*$ : 在 0.05 级别 (双尾), 相关性显著; ** : 在 0.01 级别 (双尾), 相关性显著

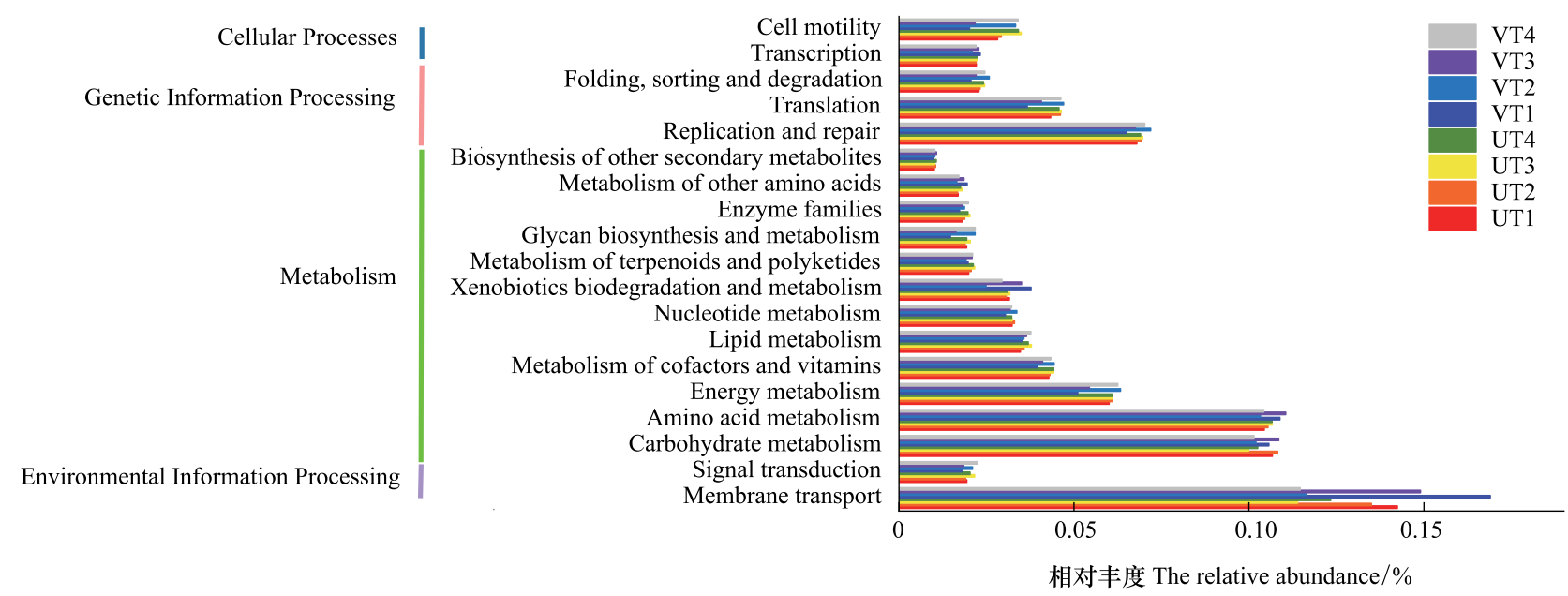

图 7 PICRUSt 预测的 KEGG 第二等级分布图

Fig.7 The secondary grade distribution map of KEGG predicted by PICRUSt

\section{3 讨论}

3.1 黄河口潮间带沉积物中细菌丰度分布特征

植物对土壤微生物的影响是非常重要的 ${ }^{[13]}$ 。本研究发现有植被覆盖沉积物中细菌丰度高于无植被覆盖 沉积物, 这与丁浩 ${ }^{[14]}$ 等的研究结果相一致。一般看来, 表层覆盖植被的土壤环境能为微生物提供适宜的栖息 场所,特别是植物死亡后的残体进人沉积土壤中, 可以为异养细菌提供丰富有效的营养物质,促进细菌的生长 和繁殖。因此相较无植被区域, 覆盖植被的土壤中细菌丰度更高 ${ }^{[15-16]}$ 。本研究沉积物中细菌丰度在垂直方 向上整体呈现先增加后降低的变化趋势, 中层丰度最高。潮水的涨落使得潮间带表层沉积物受到海陆理化因 子的交互作用 ${ }^{[17]}$, 不稳定的环境条件不利于微生物的生存, 因此表层细菌群落丰度较低。随着深度的增加, 环境条件趋于稳定,有机质逐渐累积, 为细菌提供了良好的生存环境, 细菌的数量也随之增多。而更深层次的 
沉积物虽然环境条件稳定,但是由表层沉积下来的可供细菌利用的碳源、氮源等逐层消耗而减少,细菌的生长 繁殖受到了限制, 因此其丰度又逐渐降低。

3.2 黄河口潮间带沉积物中细菌群落结构特征

对黄河口潮间带沉积物中微生物的研究一直受到国内学者的关注。刘芳等 ${ }^{[7]}$ 利用克隆文库方法和 TRFLP 技术在黄河口湿地发现大量功能菌, 如硫酸盐还原菌、光合细菌和好气分解细菌等; 王凯等 ${ }^{[9]}$ 通过 PCR-DGGE 方法发现黄河口潮滩春季的优势细菌有变形菌 (Proteobacteria)、酸杆菌 (Acidobacteria) 和一些未 分类的微生物类群。本研究利用高通量测序技术对黄河口潮间带有植被和无植被区域沉积物中细菌群落结 构进行了研究。结果发现有植被区域沉积物中细菌群落丰富度和多样性低于无植被区域, 这与两个区域丰度 结果相反。可能是因为一个环境中,优势菌的丰度较高, 会对其它非优势菌群的生存产生压迫,以致该环境细 菌群落丰富度和多样性较低。本研究发现黄河口的优势菌有变形菌、放线菌 (Actinobacteria)、绿弯菌 (Chloroflexi) 和酸杆菌等,这些均是海洋沉积物中常见的细菌类群。变形菌是细菌中最大的一个门类,通常在 中国沿海潮间带沉积物环境的微生物群落结构中占据优势地位, 例如在对大连长山群岛海岸潮间带沉积 物 ${ }^{[18]}$ 和秦皇岛南部近海潮间带沉积物 ${ }^{[19]}$ 的微生物群落结构中均发现变形菌占细菌群落的 $60 \%$ 以上, 为绝对 优势菌。变形菌中包含较多的固氮细菌, 能够提升潮间带氮循环 ${ }^{[20]}$ 。放线菌在各类土壤研究中也被广泛地 发现, 在湿地环境中相对丰度约 $2 \%-25 \%$ 。年-22]。本研究中放线菌在有植被区域表层沉积物样品中丰度较 高, 而且其相对丰度与磷酸盐含量呈显著正相关, 是因为放线菌中多数菌种为好氧腐生菌, 且具有共生固氮和 降解磷的作用 ${ }^{[23]}$, 这样更有利于分解表层土壤中的植物残体, 促进物质和能量的循环。两个站位的表层样品 中蓝细菌 (Cyanobacteria) 含量比其它层次样品中的高, 主要是因为蓝细菌含有叶绿素 $\mathrm{a}$, 沉积物表层环境更适 宜进行光合作用, 有利于其生存发展 ${ }^{[24]}$ 。拟杆菌 (Bacteroidetes) 能够降解高分子有机物 ${ }^{[25]}$, 本研究发现拟杆 菌在黄河口潮间带各样品中相对丰度较高, 这样有利于来自陆源的高分子有机污染物在潮间带降解, 减少对 海洋的污染。绿弯菌 (Chloroflexi) 是本研究中相对丰度仅次于变形菌的第二大优势菌, 有研究报道其在水合 物贫乏、有机质丰富的沉积物中为优势类群, 能够促进厌氧环境条件下的物质循环 ${ }^{[26]}$ 。

本研究在黄河口潮间带沉积物中发现大量与生态修复相关的菌属。如在表层样品中含量丰富的苍白杆 菌属 (Ochrobactrum), 其隶属于 $\alpha$-变形菌, 是一种好氧反硝化细菌 ${ }^{[26]}$, 该菌具有耐金属镉的特性 ${ }^{[27]}$, 而且在盐 碱条件下能够降解多环芳烃 ${ }^{[28]}$, 为黄河口潮间带污染土壤的生物修复提供了一种思路; 优势菌属芽孢杆菌 (Bacillus) 是一种能形成孢子结构, 具有很强的抗逆能力的菌属, 其在较高 $\mathrm{pH}$ 、低温、高盐度等恶劣环境下仍 能生存, 而且芽狍杆菌分泌的一种酶能够分解一些难分解的蛋白质、脂质等物质, 还能吸收环境中未被氧化的 氨、铵盐及硫化氢等, 常被应用于污水的生物处理中 ${ }^{[29]}$; 在有植被表层样品中的优势菌属——鞘氨醇单胞菌 (Sphingomonas), 属于变形菌门 $\alpha$ 变形菌纲, 能够降解芳香族化合物 ${ }^{[30]}$, 促进植物抵抗多种病原菌 ${ }^{[31]}$, 是清理 土壤污染物最有效的细菌之一。

滨海湿地土壤微生物具有独特的功能和基因资源, 在净化污染物、维持生态系统稳定中发挥重要作 用 ${ }^{[32]}$ 。通过 PIRCUSt 功能预测得知黄河口潮间带沉积物菌群功能丰富, 其中膜运输、碳水化合物代谢、氨基 酸代谢功能最为活跃。推测是由于潮间带沉积环境受到海水周期性淹没的影响, 只有具有活跃的膜转运调节 功能的细菌, 通过调节胞内外渗透压, 才能更好地在此生存 ${ }^{[33]}$ 。碳水化合物是生命细胞结构的主要成分, 同 时也是细胞呼吸的底物。碳水化合物代谢可以调控生物体内碳水化合物的代谢形成、分解和相互转化 ${ }^{[34]}$, 该 功能代谢旺盛说明微生物生命活动活跃。在有植被区域,植物根际会分泌有机物, 其中包括碳水化合物、氨基 酸和有机酸等 ${ }^{[35]}$, 这些物质会促进微生物的相关代谢活动, 因此有植被区域微生物碳水化合物代谢和氨基酸 代谢功能较无植被区域更为活跃。无植被区域细菌群落在核酸复制和修复、能量代谢过程较有植被更为活 跃, 可能是由于无植被潮间带没有植被的保护, 相较有植被潮间带环境复杂多变, 优势细菌只有通过加强自身 核酸复制和修复功能, 加快能量代谢, 让其菌群保持活力, 以确保其在恶劣环境中生存发展。本研究的不足之 处是只利用 PICRUSt 对潮间带表层有无植被沉积物中的细菌群落功能差异进行了初步预测, 该方法具有一 
定的局限性。想要更全面了解潮间带沉积物中细菌功能,可结合宏基因组分析进行深人研究。

\section{3 黄河口潮间带沉积物环境因子对细菌群落的影响}

土壤环境因子对微生物群落结构有重要影响。姜雪薇等 ${ }^{[36]}$ 发现土壤 $\mathrm{pH}$ 、含水量、总氮和总磷是影响土 壤微生物群落结构的重要因素; 王鹏等 ${ }^{\left[{ }^{[37}\right]}$ 认为湿地土壤细菌群落主要受有机质含量、总磷和铵态氮的影响; 张小青 ${ }^{[38]}$ 发现 $\mathrm{pH}$ 、TC 和 TN 是影响荒漠土壤细菌群落结构的主导因子。本研究结果显示黄河口潮间带盐 度、亚硝酸盐、铵盐以及磷酸盐与细菌群落多样性指数和丰富度指数表现出不同程度的相关性。盐度是影响 河口生态系统中微生物群落结构的重要因素 ${ }^{[39-40]}$, 本研究中细菌多样性指数和丰富度指数均与盐度呈显著 负相关, 可能是由于土壤盐度的增加和渗透压的提高会使某些微生物物种消失, 导致细菌群落多样性下降。 本研究中土壤 $\mathrm{pH}$ 与细菌群落结构和多样性的相关性均不显著, 与已有的研究结果不同 ${ }^{[41]}$, 可能是由于选取 的黄河口潮间带研究区域 $\mathrm{pH}$ 变化范围小, 对细菌群落结构变化的影响不明显。本研究结果显示多个优势菌 门与亚硝酸盐、磷酸盐、铵盐相关性显著, 如拟杆菌的相对丰度与铵盐含量呈极显著正相关, 因为拟杆菌中含 有多种固氮菌 ${ }^{[42]}$, 能将空气中氮气固定, 进而转化为铵盐; 绿弯菌与亚硝酸盐、磷酸盐含量呈显著负相关, 是 由于绿弯菌具有去除营养盐的功能 ${ }^{[43]}$ 。这进一步证实了土壤环境因子对细菌群落结构具有重要影响。

\section{4 结论}

(1) 黄河口潮间带沉积物中细菌丰度在不同深度差异较大, 总体表现为随深度的增加细菌丰度先升高后 降低的趋势。有植被区域丰度为 $3.55 \times 10^{5}-1.29 \times 10^{7}$ 拷贝数 $/ \mathrm{g}$, 无植被区域为 $5.76 \times 10^{2}-4.23 \times 10^{6}$ 拷贝数 $/ \mathrm{g}$, 表明植被及沉积物深度是影响沉积物中细菌丰度的重要因素。

(2) 黄河口潮间带有植被区域检测到 50 个细菌门,无植被区域检测到 56 个细菌门,优势菌门有变形菌、 放线菌、酸杆菌等。属水平上优势菌 Ochrobactrum 和 Sphingomonas 独特的代谢功能能够降解盐碱沉积物中的 有机污染物,可以通过微生物培养方法将其应用到潮间带生态系统修复工程中。

\section{参考文献 (References)：}

[ 1 ] Yu J B, Zhan C, Li Y Z, Zhou D, Fu Y Q, Chu X J, Xing Q H, Han G X, Wang G M, Guan B, Wang Q. Distribution of carbon, nitrogen and phosphorus in coastal wetland soil related land use in the Modern Yellow River Delta. Scientific Reports, 2016, 6: 37940.

[ 2 ] Kirchman D L, Cottrel M T, DiTullio G R. Shaping of bacterial community composition and diversity by phytoplankton and salinity in the Delaware Estuary, USA. Aquatic Microbial Ecology, 2016, 78(2): 93-106.

[ 3 ] Decho A W. Microbial biofilms in intertidal systems: an overview. Continetal Shelf Research, 2000, 20(10/11): 1257-1273.

[ 4 ] Lynch J M, Whipps J M. Substrate flow in the rhizosphere. Plant soil, 1990, 129(1): 1-10.

[ 5 ] 戴良香, 康涛, 慈敦伟, 丁红, 徐扬, 张智猛, 张岱, 李文金. 黄河三角洲盐碱地花生根层土壤菌群结构多样性. 生态学报, 2019,39 (19) : 7169-7178.

[ 6 ] 顾国海, 李梦莎. 滨海不同湿地类型土壤微生物功能多样性. 江苏农业科学, 2018, 46(24): 355-358.

[ 7 ] 刘芳, 叶思源, 汤岳琴, 滝川清, 木田建次, 吴晓否. 黄河三角洲湿地土壤微生物群落结构分析. 应用与环境生物学报, 2007, 13(5)： 691- 696 .

[ 8 ] 王震宇, 辛远征, 李锋民, 高冬梅. 黄河三角洲退化湿地微生物特性的研究. 中国海洋大学学报, 2009, 39(5): 1005-1012.

[ 9 ] 王凯, 邹立, 高冬梅, 刘陆. 黄河口潮滩春季细菌群落的分布特征及其影响因素研究. 中国海洋大学学报, 2016, 46(1) : 108-115.

[10］车玉伶, 王慧, 胡洪营, 梁威, 郭玉凤. 微生物群落结构和多样性解析技术研究进展. 生态环境, 2005, 14(1): 127-133.

[11] Peiffer J A, Spor A, Koren O, Jin Z, Tringe S G, Dangl J L, Buckler E S, Ley R E. Diversity and heritability of the maize rhizosphere microbiome under field conditions. Proceedings of the National Academy of Sciences of the United States of America, 2013, 110(16) : 6548-6553.

[12] Han L, Zhang H P, Long Z N, Ge Q Q, Mei J J, Yu Y L, Fang H. Exploring microbial community structure and biological function in manured soil during ten repeated treatments with chlortetracycline and ciprofloxacin. Chemosphere, 2019, 228: 469-477.

[13] 章振亚, 丁陈利, 肖明. 崇明东滩湿地不同潮汐带人侵植物互花米草根际细菌的多样性. 生态学报, 2012, 32(21): 6636-6646.

[14］丁浩, 凌云, 徐亚同, 米文秀. 梦清园芦苇湿地根际微生物特性研究. 四川环境, 2007, 26(2): 6-10.

[15] 庄铁诚, 林鹏. 红树林调落叶自然分解过程中土壤微生物的数量动态. 厦门大学学报: 自然科学版, 1993, 32(3): 365-370 
[16] 张瑜斌, 王文卿, 庄铁诚, 林鹏. 厦门西港西南部潮间带光滩土壤微生物的数量变化. 台湾海峡, 2000, 19(1): 54-59.

[17] Webb E L, Friess D A, Krauss K W, Cahoon D R, Guntenspergen G R, Phelps J. A global standard for monitoring coastal wetland vulnerability to accelerated sea-level rise. Nature Climate Change, 2013, 3(5): 458-465.

[18］李佳霖, 王中华, 秦松, 汪光义. 大连长山群岛海岸带沉积物微生物群落结构特征. 微生物学报, 2011, 51(5): 656-666.

[19］李佳霖, 汪光义, 秦松. 秦皇岛近海养殖对潮间带微生物群落多样性的影响. 生态环境学报, 2011, 20(5): 920-926.

[20] Yang W, Jeelani N, Zhu Z H, Luo Y Q, Cheng X L, An S Q. Alterations in soil bacterial community in relation to Spartina alterniflora Loisel. invasion chronosequence in the eastern Chinese coastal wetlands. Applied Soil Ecology, 2019, 135: 38-43.

[21] Zhou Z C, Meng H, Liu Y, Gu J D, Li M. Stratified bacterial and archaeal community in mangrove and intertidal wetland mudflats revealed by high throughput 16S rRNA gene sequencing. Frontiers in Microbiology, 2017, 8: 2148.

[22] Cheung M K, Wong C K, Chu K H, Kwan H S. Community structure, dynamics and interactions of bacteria, archaea and fungi in subtropical coastal wetland sediments. Scientific Reports, 2018, 8(1): 14397.

[23] Juhnke M E, Mathre D E, Sands D C. Identification and characterization of rhizosphere-competent bacteria of Wheat. Applied and Environmental Microbiology, 1987, 53(12): 2793-2799.

[24] 刘宪斌, 杨莹, 李中媛, 林颖青. 渤海昌黎近岸海域水中微生物群落多样性分析. 安全与环境学报, 2019, 19(5): 1817-1823.

[25] Cottrell M T, Kirchman D L. Natural assemblages of marine proteobacteria and members of the Cytophaga-Flavobacter cluster consuming low- and high-molecular-weight dissolved organic matter. Applied and Environmental Microbiology, 2000, 66(4) : 1692-1697.

[26] Teyssier C, Marchandin H, Masnou A, Jeannot J L, Siméon De Buochberg M, Jumas-Bilak E. Pulsed-field gel electrophoresis to study the diversity of whole-genome organization in the genus Ochrobactrum. Electrophoresis, 2005, 26(15) : 2898-2907.

[27] Pandey S, Ghosh P K, Ghosh S, De T K, Maiti T K. Role of heavy metal resistant Ochrobactrum sp. and Bacillus spp. strains in bioremediation of a rice cultivar and their PGPR like activities. Journal of Microbiology, 2013, 51(1) : 11-17.

[28] Arulazhagan P, Vasudevan N. Biodegradation of polycyclic aromatic hydrocarbons by a halotolerant bacterial strain Ochrobactrum sp. VA1. Marine Pollution Bulletin, 2011, 62(2): 388-394.

[29］李奇聪, 赵玉华, 修㿟月, 胡光楠. 某市第一污水厂工艺改造工程实例. 建筑与预算, 2015, (11) : 47-49.

[30］苟敏, 曲媛媛, 杨桦, 周集体, 李昂, 关晓燕, 艾芳芳. 鞘氨醇单胞菌: 降解芳香化合物的新型微生物资源. 应用与环境生物学报, 2008, $14(2): 276-282$

[31] Adhikari T B, Joseph C M, Yang G P, Phillips D A, Nelson L M. Evaluation of bacteria isolated from rice for plant growth promotion and biological control of seedling disease of rice. Canadian Journal of Microbiology, 2001, 47(10) : 916-924.

[32] 解雪峰, 项琦, 吴涛, 蒋国俊, 孙晓敏, 朱明, 兴励杰. 滨海湿地生态系统土壤微生物及其影响因素研究综述. 生态学报, 2021, 41( 1) : 1- 12 .

[33] Bhattacharya S. Handbook of cell signaling. Journal of Anatomy, 2004, 205(1) : 77-77.

[34] 孙晓, 林余霖, 李㭉莉, 黄林芳. 干旱区沙生药用植物锁阳土壤微生物群落分析与功能预测. 药学学报, 2020, 55(6): 1334-1344.

[35］朱丽霞, 章家恩, 刘文高. 根系分泌物与根际微生物相互作用研究综述. 生态环境, 2003, 12(1) : 102- 105.

[36] 姜雪薇, 马大龙, 藏淑英, 张冬有, 孙弘哲. 高通量测序分析大兴安岭典型森林土壤细菌和真菌群落特征. 微生物学通报, 2021, 48(4): 1093-1105.

[37] 王鹏, 陈波, 张华. 基于高通量测序的鄱阳湖典型湿地土壤细菌群落特征分析. 生态学报, 2017, 37(5): 1650- 1658.

[38］张小青. 荒漠植被土壤细菌群落结构与多样性研究 [D]. 呼和浩特: 内蒙古大学, 2019.

[39] Li M, Cao H L, Hong Y G, Gu J D. Using the variation of anammox bacteria community structures as a bio-indicator for anthropogenic/terrestrial nitrogen inputs in the Pearl River Delta (PRD). Applied Microbiology and Biotechnology, 2013, 97(22) : 9875-9883.

[40] Jia J, Bai J H, Gao H F, Wen X J, Zhang G L, Cui B S, Liu X H. In situ soil net nitrogen mineralization in coastal salt marshes (Suaeda salsa) with different flooding periods in a Chinese estuary. Ecological Indicators, 2017, 73: 559-565.

[41］王鹏,肖汉玉,张华,等. 鄱阳湖人湖河口沉积物细菌群落特征. 中国环境科学, 2018, 38(4): 1481-1489.

[42] He D, Ren L J, Wu Q L. Contrasting diversity of epibiotic bacteria and surrounding bacterioplankton of a common submerged macrophyte, Potamogeton crispus, in freshwater lakes. FEMS Microbiology Ecology, 2014, 90(3) : 551-562.

[43] Ma Q, Qu Y, Zhang X W, Shen W L, Liu Z Y, Wang J W, Zhang Z J, Zhou J T. Identification of the microbial community composition and structure of coal-mine wastewater treatment plants. Microbiological Research, 2015, 175: 1-5. 